\title{
Semi-empirical model for retrieval of soil moisture using RISAT-1 C-Band SAR data over a sub-tropical semi-arid area of Rewari district, Haryana (India)
}

\author{
Kishan Singh Rawat ${ }^{1,2, *^{(D}, \text { Vinay Kumar }_{\text {Sehgal }}{ }^{1} \text { (D), Sanatan Pradhan }}{ }^{1}$ \\ and SHIBENDU S RAY ${ }^{3}$ \\ ${ }^{1}$ Division of Agricultural Physics, Indian Agricultural Research Institute, New Delhi 110 012, India. \\ ${ }^{2}$ Center for Remote Sensing and Geo-Informatics, Satyabama University, Chennai 600 119, India. \\ ${ }^{3}$ Mahalanobis National Crop Forecast Centre (MNCFC), Pusa Campus, New Delhi 110 012, India. \\ *Corresponding author. e-mail: kr_rawat2002@yahoo.com
}

MS received 26 August 2016; revised 28 March 2017; accepted 24 June 2017; published online 2 March 2018

We have estimated soil moisture (SM) by using circular horizontal polarization backscattering coefficient $\left(\sigma_{\mathrm{RH}}^{\mathrm{o}}\right)$, differences of circular vertical and horizontal $\sigma^{\mathrm{o}}\left(\sigma_{\mathrm{RV}}^{\mathrm{o}}-\sigma_{\mathrm{RH}}^{\mathrm{o}}\right)$ from FRS-1 data of Radar Imaging

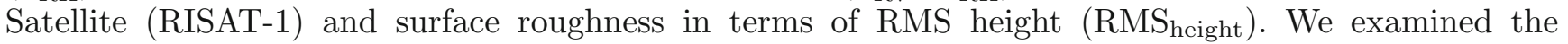
performance of FRS-1 in retrieving SM under wheat crop at tillering stage. Results revealed that it is possible to develop a good semi-empirical model (SEM) to estimate SM of the upper soil layer using RISAT-1 SAR data rather than using existing empirical model based on only single parameter, i.e., $\sigma^{\circ}$. Near surface SM measurements were related to $\sigma_{\mathrm{RH}}^{\mathrm{o}}, \sigma_{\mathrm{RV}}^{\mathrm{o}}-\sigma_{\mathrm{RH}}^{\mathrm{o}}$ derived using $5.35 \mathrm{GHz}$ (C-band) image

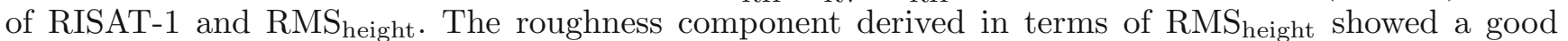
positive correlation with $\sigma_{\mathrm{RV}}^{\mathrm{o}}-\sigma_{\mathrm{RH}}^{\mathrm{o}}\left(R^{2}=0.65\right)$. By considering all the major influencing factors $\left(\sigma_{\mathrm{RH}}^{\mathrm{o}}\right.$, $\sigma_{\mathrm{RV}}^{\mathrm{o}}-\sigma_{\mathrm{RH}}^{\mathrm{o}}$, and $\mathrm{RMS}$ height), an SEM was developed where SM (volumetric) predicted values depend on $\sigma_{\mathrm{RH}}^{\mathrm{o}}, \sigma_{\mathrm{RV}}^{\mathrm{o}}-\sigma_{\mathrm{RH}}^{\mathrm{o}}$, and $\mathrm{RMS}_{\text {height }}$. This SEM showed $R^{2}$ of 0.87 and adjusted $R^{2}$ of 0.85 , multiple $R=0.94$ and with standard error of 0.05 at $95 \%$ confidence level. Validation of the SM derived from semi-empirical model with observed measurement $\left(\mathrm{SM}_{\text {Observed }}\right)$ showed root mean square error $(\mathrm{RMSE})=0.06$, relativeRMSE $($ R-RMSE) $=0.18$, mean absolute error $(\mathrm{MAE})=0.04$, normalized RMSE $(\mathrm{NRMSE})=0.17$, Nash-Sutcliffe efficiency $(\mathrm{NSE})=0.91(\approx 1)$, index of agreement $(\mathrm{d})=1$, coefficient of determination $\left(R^{2}\right)=0.87$, mean bias error $(\mathrm{MBE})=0.04$, standard error of estimate $(\mathrm{SEE})=0.10$, volume error $(\mathrm{VE})=0.15$, variance of the distribution of differences $\left(\mathrm{S}_{\mathrm{d}}^{2}\right)=0.004$. The developed SEM showed better performance in estimating SM than Topp empirical model which is based only on $\sigma^{\circ}$. By using the developed SEM, top soil SM can be estimated with low mean absolute percent error (MAPE) $=1.39$ and can be used for operational applications.

Keywords. Soil moisture; SAR; RISAT-1; TDR; semi-empirical model.

Supplementary material pertaining to this article is available on the Journal of Earth System Science website (http://www. ias.ac.in/Journals/Journal_of_Earth_System_Science). 


\section{Introduction}

Microwave remote sensing technique has showed great potential in agricultural applications such as crop yield estimation, forecasting, irrigation management, and issuing early warning of droughts. Substantial progress has been made in terms of vegetation classification and monitoring from hyperspectral visible/infrared remote sensing (RS). However, considering the limitations of hyperspectral RS under cloud cover, its combination with microwave (MW) data for routine measurement of SM and vegetation distinctiveness has great potential for agriculturists and hydrologists.

Vegetation dynamics, atmospheric sciences, and hydrological studies need accurate and up-to-date information of soil surface conditions, SM and surface roughness. Under this background, satellite imagery acts as a powerful tool by providing accurate and repeated spatial data. Synthetic Aperture Radar (SAR) data analysis technique can be used to examine soil parameters under complex weather conditions. The backscattered SAR signal strongly depends on the geometric characteristics and dielectric properties of the soil in bare agricultural land. Zribi and Dechambre (2002) have found in their experimental analysis that the radar signal is more sensitive to surface roughness at high incidence angles than at low incidence angles and findings were supported by Baghdadi et al. (2012) and Fung (1994).

In SAR technology, the radar signal follows a logarithmic function with the soil surface roughness. The radar signal and roughness parameter have more strong relationship in the L-band (0.5$1.5 \mathrm{GHz})$ followed by the C-band $(4-8 \mathrm{GHz})$ and lowest in X-band $(8-12 \mathrm{GHz})$ and are more sensitive to soil roughness at high incidence angles (Zribi and Dechambre 2002; Baghdadi et al. 2012; Hosseini et al. 2015; Dente 2016; Liu 2016).

The surface roughness is a measure of the irregularities of the surface geometry which has a significant effect on the variation of radar backscattering/returning signal amount. The degree of roughness or smoothness of a surface depends on the wavelength of the incidence energy. Higher surface roughness increases the backscattering by increasing the total emitting surface. The dependency of the dielectric constant $\left(\varepsilon_{r}\right)$ on soil texture is primarily a function of variation of water retention by soil particles (Ulaby et al. 1978; Zhang et al. 2016). The sensitivity of soil texture to dielectric constant is lower in dry soil and higher in wet soil conditions. Different soil textures have distinct patterns of soil moisture content and soil drainage. Soil texture is closely related to spatial and temporal dynamics of SM. In general, precipitation is responsible for SM variability at a larger scale and soil texture controls this variability at a smaller scale. Vegetation cover is the most important factor that influences the retrieval of soil moisture from MW RS. Previous studies (Neusch and Sties 1999; Sikdar and Cumming 2004) revealed that radar signals of C-band are not significantly affected if vegetation has $<0.4$ NDVI value.

The aim of this work was to derive a semiempirical model to retrieve SM (volumetric) by using FRS-1 data of RISAT-1 (SAR technologybased Indian satellite). This SEM was developed by considering the major influencing factors to retrieve SM in terms of soil physical characteristics (surface roughness) and backscattering coefficient of RH polarization. It may be noted that RV polarizations were not used, because we found in a previous study that vertical component of radar signal do not carry enough information for SM study (Rawat et al. 2017a).

\section{Materials and methods}

\subsection{Study area description}

The study area lies between $76^{\circ} 29^{\prime}-76^{\circ} 44^{\prime} \mathrm{E}$ and $28^{\circ} 17^{\prime}-28^{\circ} 36^{\prime} \mathrm{N}$, with altitude of $245 \mathrm{~m}$ above mean sea level in Rewari district (geographical area $1559 \mathrm{~km}^{2}$, shown in figure 1) in the state of Haryana, India. The study was conducted during rabi season (Nov-Mar) when most of the region was under wheat crop. The main sources of irrigation are canals $(2.1 \%)$ and bore-wells/tube wells $(96.9 \%)$. The average annual rainfall of the district is $657.3 \mathrm{~mm}$. The average rainfall in last 10 years in the district was $569.6 \mathrm{~mm}$ (DDMP Rewari-2013). The rainfall distribution in the district is uneven and scattered which results in drought conditions often, in turn, affecting the agricultural production as well as cropping pattern in kharif and rabi seasons (DDMP Rewari-2013).

\subsection{Data processing}

TARANG software was used for pre-processing of FRS-1 SAR images with RV and RH polarization. This software is jointly developed by IIT-B and SAC (ISRO) and is the advanced version of Polarimetric SAR data processing (PolSDP) 
(a)

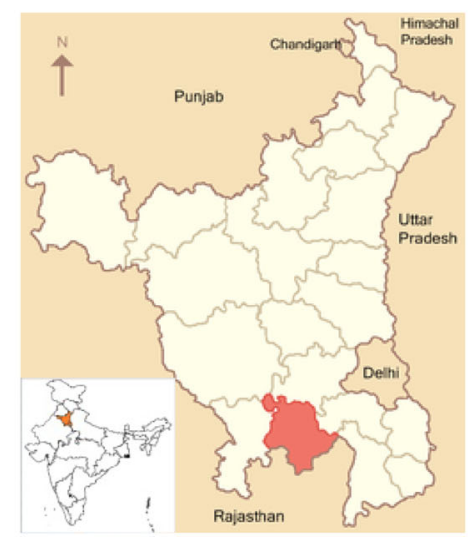

(b)

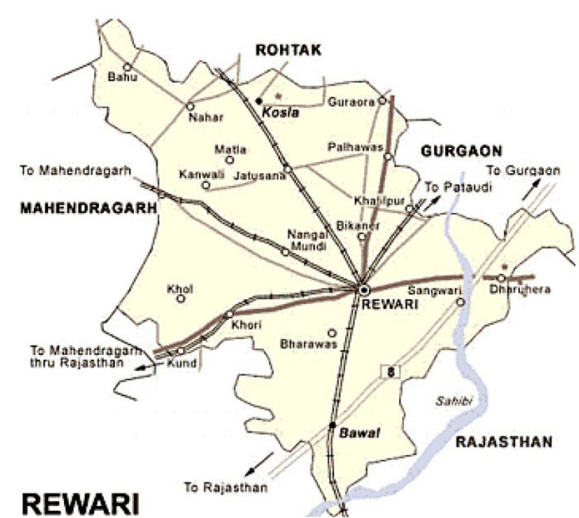

(c)

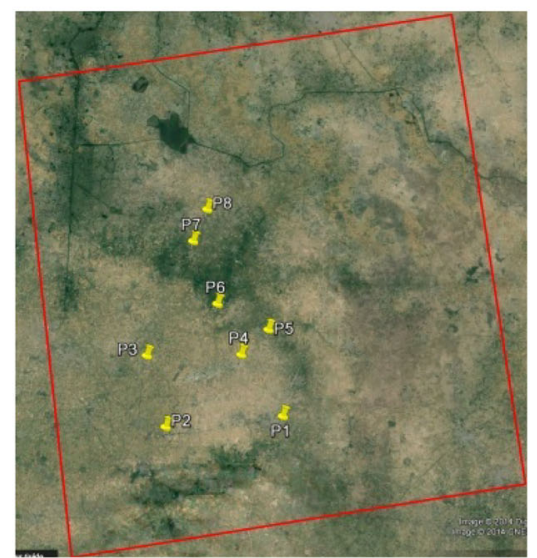

Figure 1. Study area location (a) Haryana (inset India), (b) Rewari district map, and (c) SM measurement points during ground truth and RISAT-1 swath (polygon) over Google Image.

Table 1. Metadata extracted from RISAT-1 (FRS-1) dataset using TARANG software.

\begin{tabular}{ll}
\hline Azimuth looks & 1 \\
\hline Range looks & 1 \\
Multi looks & 1.073144 \\
Ground pixel spacing & 2.271846 \\
Range pixel spacing & 1.801 \\
Line spacing & 2.117 \\
Centre incidence angle & 52.443 \\
Scene centre (long.) & 76.619992 \\
Scene centre (lat.) & 28.444275 \\
Multi looks (during processing) & \\
Range & 1 \\
Azimuth & 1 \\
Color scheme & $\mathrm{R}: \mathrm{C}_{11}$ based
\end{tabular}

software which was developed by IIT-B. It is capable of handling RISAT-1 datasets with all required metadata information in text format (table 1). The software converts the $\mathrm{RH}$ and $\mathrm{RV}$ files into scattering matrix. While converting the RISAT-1 (FRS-1) data, it uses calibration factor which were 67.768 and 64.414 for $\mathrm{RH}$ and RV images for our case, respectively.

\subsubsection{Power image generation of RISAT-1 (FRS-1) dataset}

Level 1 single look complex dataset was acquired from National Remote Sensing Centre (NRSC), Hyderabad. The $I$ and $Q$ values for each pixel were supplied as 16 bit integers. The image data was imported and converted into a complex floating point dataset. Then suitable calibration equations were applied for radiometric correction of data. The calibration constant $\left(K_{\mathrm{dB}}\right)$ was supplied with the data as metadata (67.768 and 64.414 for $\mathrm{RH}$ and RV, respectively) and is in decibel scale. To get power values for each pixel, we used the following relations:

$$
D N_{p}=\sqrt{\left(I^{2}+Q^{2}\right)} .
$$

\section{Decibel (dB) scale}

Backscatter $\left(\sigma^{\circ}\right)$ in $\mathrm{dB}$ scale was calculated using equation (2) and its image is shown in figure 2.

$$
\sigma^{\mathrm{o}}=20 \log _{10} D N_{p}-K_{d B}+10 \log _{10}\left(\sin \theta_{i} / \sin \theta_{c}\right)
$$

where $D N_{p}$ is the digital number or power image, $\theta_{i}$ is the local incidence angle, and $\theta_{c}$ is the incidence angle at image centre.

\subsubsection{Time domain reflectometry (TDR)}

A TDR measures reflection along a conductor inserted in soil (wet/dry). In order to measure those reflections, the TDR transmits an incident signal onto the conductor and observe its reflection. If the conductor is of uniform impedance and is properly terminated, then there will be no reflections and the remaining incident signal will be absorbed at the far-end by the termination. Instead, if there are impedance variations, then some of the incident signals will be reflected back to the source. Radar has similar kind of principle (Nussberger 2005; Rawat et al. 2017a). Therefore, Field Scout ${ }^{\mathrm{TM}}$ TDR 300 Soil Moisture Meter instrument was used in the present study (figure 3). The TDR was used for obtaining point SM 


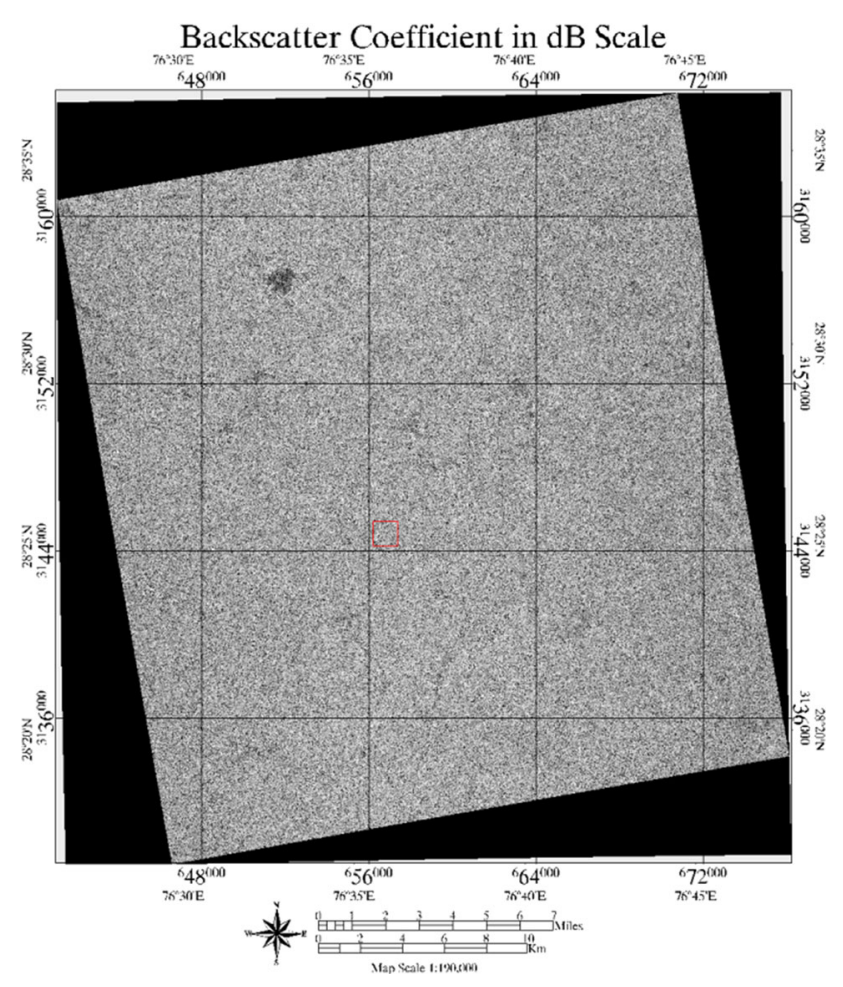

Figure 2. Backscattering coefficient $\left(\sigma^{\circ}\right)$ image of study area in $\mathrm{dB}$ scale.

measurements from the fields in the study area. Before undertaking field measurements, the TDR was calibrated in the experimental farm of Division of Agriculture Physics, IARI, New Delhi by developing a relation between TDR measurement of time of reflection and volumetric soil moisture.

\subsubsection{Generation of dielectric constants $\left(\varepsilon_{r}\right)$ using Hallikainen model}

According to Hallikainen et al. (1985), $\varepsilon_{r}$ can be generated for a particular MW frequency (in case of RISAT-1, 5.3 GHz) on the basis of SM and soil texture properties. Hallikainen model is given as:

$$
\begin{aligned}
\varepsilon_{r}= & \left(a_{0}+a_{1} S+a_{2} C\right)+\left(b_{0}+b_{1} S+b_{2} C\right) \times m_{v} \\
& +\left(c_{0}+c_{1} S+c_{2} C\right) \times m_{v}^{2}
\end{aligned}
$$

where $a_{i}, b_{i}$ and $c_{i}$ are coefficients (table 2), $\varepsilon_{r}$ is observed dielectric constant of soil, $m_{v}$ is volumetric SM and $S$ and $C$ are volume fraction of sand and clay (by wt.\%) present in the soil. The soil of the study area comprises of sand $70-85 \%$ (average $78 \%$ ) and clay $12-16 \%$ (average 14\%) according to previous study.

\subsection{Dielectric mixing semi-empirical model}

Most of the models use dielectric constant as one of their unknown parameters. When volumetric SM is desired, we have to use a dielectric mixing model to convert $\varepsilon_{r}$ values to volumetric SM values (Barrett et al. 2009). One of the most commonly used models is given by Topp et al. (1980). Topp model requires only $\varepsilon_{r}$ for estimation of soil water content via a third order polynomial equation as shown below:

$$
\begin{aligned}
\mathrm{SM}_{\text {Topp }}= & -5.3 \times 10^{-2}+2.92 \times 10^{-2} \varepsilon_{r} \\
& -5.5 \times 10^{-4} \varepsilon_{r}^{2}+4.3 \times 10^{-6} \varepsilon_{r}^{3}
\end{aligned}
$$

where $\mathrm{SM}_{\text {Topp }}$ is the volumetric $\mathrm{SM}$ from Topp model.

This advantage makes the later model more widely used because only $\varepsilon_{r}$ input data is required and another advantage of this model is its easy linking with Hallikainen model because coefficients $\left(a_{i}, b_{i}\right.$ and $c_{i}$, given in table 2$)$ of equation (3) are already defined by Hallikainen et al. (1985) at RISAT-1 frequency of $5.3 \mathrm{Ghz}$. We have adopted both model equations ( 3 and 4 ) in this study.

\subsection{Soil surface roughness (SSR)}

In this study, soil surface roughness (SSR) was measured using the chain method (Saleh 1993). This method is the simplest and most convenient way to estimate SSR (Werrer and Andreas 2005). It is based on the fact that horizontal length decreases as SSR increases when a chain of given length $L_{1}$ is laid on the surface. Therefore, SSR could be measured by calculating decrements in the chain length using the equation below:

$$
\mathrm{SSR}=\left(1-\frac{L_{1}}{L_{2}}\right) \times 100
$$

where SSR is soil surface roughness at any direction. However, roughness caused by aggregates (random roughness) was obtained by measuring the SSR in perpendicular direction to ridges. $L_{1}$ is the length of roller chain and $L_{2}$ is the linear distance of chain due to roughness. SSR was explained by the statistical parameter as root mean square (RMS) height (vertical variation) and calculated using the equation below:

$$
\mathrm{RMS}=\sqrt{\frac{1}{n-1}\left[\sum_{i=0}^{n}\left(Z_{i}-Z\right)^{2}\right]}
$$




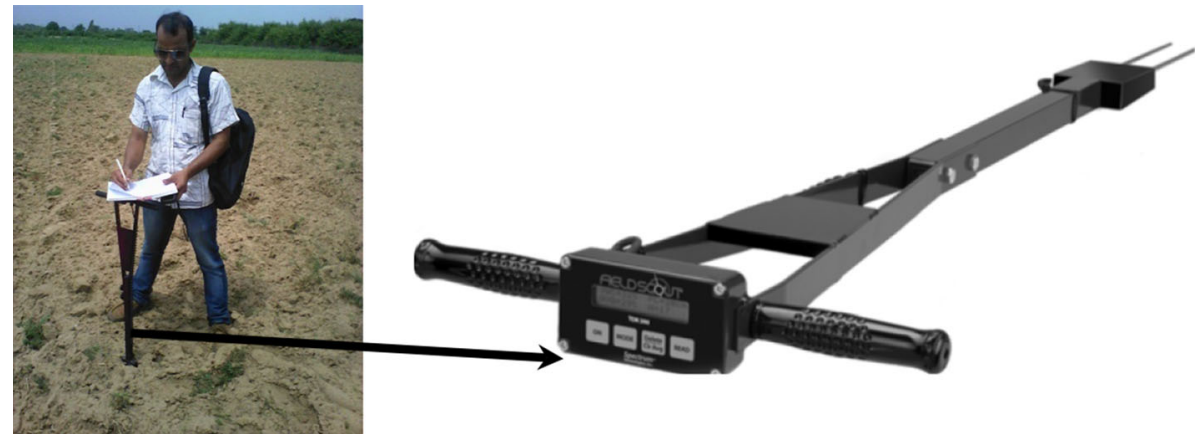

Figure 3. Time domain reflectometry (TDR) instrument (Field Scout TDR 300) used in the study.

Table 2. The look-up table for coefficients $a_{i}, b_{i}$ and $c_{i}$ at three frequencies (source, Hallikainen et al. 1985).

\begin{tabular}{lccccccccc}
\hline & \multicolumn{6}{c}{$\varepsilon=\left(a_{0}+a_{1} S+a_{2} C\right)+\left(b_{0}+b_{1} S+b_{2} C\right) \times m_{v}+\left(c_{0}+c_{1} S+c_{2} C\right) \times m_{v}^{2}$} \\
\cline { 2 - 10 } Frequency $(\mathrm{GHz})$ & $a_{0}$ & $a_{1}$ & $a_{2}$ & $b_{0}$ & $b_{1}$ & $b_{2}$ & $c_{0}$ & $c_{1}$ & $c_{2}$ \\
\hline 1.4 & 2.378 & 0.326 & -0.046 & 10.75 & 59.894 & 15.703 & 73.555 & -58.372 & -14.154 \\
$5.3(\approx$ RISAT-1, C band $)$ & 2.388 & 0.348 & -0.033 & 10.418 & 56.211 & 14.75 & 68.507 & -54.968 & -13.351 \\
6.9 & 2.395 & 0.361 & -0.025 & 10.188 & 53.775 & 14.119 & 65.18 & -52.714 & -12.819 \\
\hline
\end{tabular}

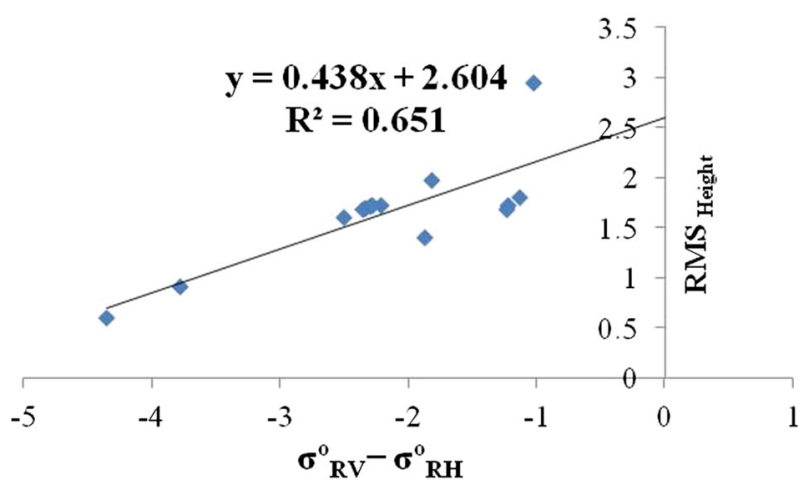

Figure 4. Relationship between $\sigma_{\mathrm{RV}}^{\mathrm{o}}-\sigma_{\mathrm{RH}}^{\mathrm{o}}$ and $\mathrm{RMS}$ Height.

where $Z_{i}$ denotes the height of the point, $Z$ is the mean height and $n$ is the total number of points taken under consideration.

SSR is explained as the surface height variance compared to a smooth SSR. SSR and SM are two important factors that affect $\sigma^{\circ}$ from bare agricultural fields (Ulaby et al. 1978), hence SSR factor is essential for estimating SM from $\sigma^{\circ}$. In the present study, SSR is modeled using $\sigma_{\mathrm{RV}}^{\mathrm{o}}-\sigma_{\mathrm{RH}}^{\mathrm{o}}$ approach.

In this study, $\sigma_{\mathrm{RV}}^{\mathrm{o}}-\sigma_{\mathrm{RH}}^{\mathrm{o}}$ was used for retrieving roughness. The ground measured RMS height values were plotted against the $\sigma_{\mathrm{RV}}^{\mathrm{O}}-\sigma_{\mathrm{RH}}^{\mathrm{O}}$ and it correlated well as shown in figure 4 with $R^{2}$ value of 0.65 . The roughness measurements were performed next day of RISAT-1 pass over the study area because it was assumed that roughness does not change within one day. The $\sigma_{\mathrm{RV}}^{\mathrm{o}}-\sigma_{\mathrm{RH}}^{\mathrm{o}}$ was used because the $\sigma_{\mathrm{RV}}^{\mathrm{o}}$ backscattering coefficient can account for the backscattering from vegetation biomass. So, by including $\sigma_{\mathrm{RV}}^{\mathrm{o}}$, the effect from the overlaying vegetation could be minimized and the possibility of getting $\sigma^{\circ}$ from the soil surface improves.

\subsection{Model evaluation}

In the present study, the developed SEM was evaluated with observed and Topp model based SM with the help of statistics as expressed in table 3 . These are coefficient of determination $\left(R^{2}\right)$, p-test, multiple $R$, adjusted $R^{2}$, standard error of estimate (SEE), root mean square error (RMSE), relativeRMSE (R-RMSE (Rawat et al. 2013, 2017a, b; Bala et al. 2015)), percent RMSC (\%RMSE), $t$-statistic test, volume error (VE), normalized RMSE (NRMSE), mean absolute error (MAE), mean bias error (MBE), mean absolute percent error (MAPE), index of agreement (d), NashSutcliffe efficiency (NSE), average index ratio (IR), percent of error (PE), and variance of the distribution of differences $\left(\mathrm{S}_{\mathrm{d}}^{2}\right)$.

\subsection{Ground measurements}

Ground measurements collected by TDR was used for calibration and validation of the models. TDR data was collected from the top soil $(0-5 \mathrm{~cm})$ only because TDR observation strategy was to investigate $\mathrm{SM}$ variations along the liner and further use it to calibrate the RISAT-1 (FRS-1) retrieval models for $0-5 \mathrm{~cm}$ penetration depth of the signal. 
Table 3. Mathematical expression of statistical tests.

Coefficient of determination $\left(R^{2}\right)$

p-test

Multiple $R$

Adjusted $R^{2}$

Standard error of estimate (SEE)

Root mean square error (RMSE)

Relative-RMSE (R-RMSE)

Percent RMSC (\%RMSE)

t-statistic test

Volume Error (VE)

Correlation coefficient (CORR\%)

Normalized RMSE (NRMSE)

Mean absolute error (MAE)

Mean bias error (MBE)

Mean absolute percent error (MAPE)

Index of agreement $(d)$

Nash-Sutcliffe efficiency (NSE)

Average index ratio (IR)

Percent of error (PE)

Variance of the distribution of differences $\left(S_{d}^{2}\right)$
$R^{2}=\left(\frac{\sum_{i=1}^{n}\left(V_{M}-\bar{V}_{M}\right) \times\left(V_{O}-\bar{V}_{O}\right)}{\sqrt{\sum_{i=1}^{n}\left(V_{M}-\bar{V}_{M}\right)^{2} \sum_{i=1}^{n}\left(V_{O}-\bar{V}_{O}\right)^{2}}}\right)^{2}$

The p-value approach involves determining 'likely' or 'unlikely' by determining the probability. If the p-value is small, say less than (or equal to) $\alpha$, then it is 'unlikely'. And, if the p-value is large, say more than $\alpha$, then it is 'likely'

Multiple $R$ is the correlation between variable and average of variable. It ranges between 0 and 1 (it won't be negative)

Adjusted $R^{2}=1-\left(1-R^{2}\right) \times \frac{n-1}{n-k-1}$

$k$ is the number of variables in the unconstrained model, $n$ is total number of variables

$\mathrm{SEE}_{\mathrm{M}}=\left(\frac{\sum_{i=1}^{n}\left(V_{O}-V_{M}\right)^{2}}{n-1}\right)^{0.5}$

$\mathrm{RMSE}=\sqrt{\left(n^{-1} \sum_{i=1}^{n}\left(V_{M}-V_{O}\right)^{2}\right)}$

$\mathrm{R}-\mathrm{RMSE}=\sqrt{\left(n^{-1} \sum_{i=1}^{n}\left(\frac{V_{M}-V_{O}}{V_{M}}\right)^{2}\right)}$

$\% \mathrm{RMSE}=\left(\frac{\mathrm{RMSE}}{\sum_{i=1}^{n}\left(V_{O}\right)} \times 100\right)$

$t=\sqrt{\left(\frac{(n-1) \mathrm{MBE}^{2}}{\mathrm{RMSE}^{2}-\mathrm{MBE}^{2}}\right)}$

$\mathrm{VE}=n^{-1} \sum_{i=1}^{n}\left|\frac{V_{O}-V_{M}}{V_{M}}\right|$

$\operatorname{CORR} \%=\frac{\operatorname{Cov}\left(V_{M}, V_{O}\right)}{\sigma_{V_{M}} \times \sigma_{V_{O}}}$

$\mathrm{NRSME}=\frac{\sqrt{\left(n^{-1} \sum_{i=1}^{n}\left(V_{M}-V_{O}\right)^{2}\right)}}{\overline{V_{O}}}$

$\mathrm{MAE}_{M}=\frac{\sum_{i=1}^{n}\left|V_{O}-\overline{V_{M}}\right|}{n}$

$\mathrm{MBE}_{M}=\frac{\sum_{i=1}^{n}\left(V_{M}-E V_{O}\right)}{n}$

$\operatorname{MAPE}_{M}=\frac{\sum_{i=1}^{n}\left|\frac{V_{O}-V_{M}}{V_{O}} \times 100\right|}{n}$

$d=1-\frac{\sum_{i=1}^{n}\left(V_{M}-V_{O}\right)^{2}}{\sum_{i=1}^{n}\left(\left|V_{M}-\overline{V_{O}}\right|+\left|V_{O}-\overline{V_{O}}\right|\right)^{2}}$

$\mathrm{NSE}=1-\frac{\sum_{i=1}^{n}\left(V_{M}-V_{O}\right)^{2}}{\sum_{i=1}^{n}\left(V_{O}-\bar{V}_{O}\right)^{2}}$

$\mathrm{IR}=\frac{V_{M}}{V_{O}}$

$\mathrm{PE}=\left(\frac{V_{M}-V_{O}}{V_{O}}\right) \times 100$

$S_{d}^{2}=\frac{\sum_{i=1}^{n}\left(V_{M}-V_{O}-\sum_{i=1}^{n} \frac{\left(V_{M}-V_{O}\right)}{n}\right)^{2}}{n-1}$

$V_{O}$ is the, observed value and $V_{M}$ is the model value.

\section{Results and discussion}

\subsection{Factor statistics}

\subsubsection{Backscattering coefficient $\left(\sigma^{\circ}\right)$}

The $\sigma^{\mathrm{O}}$ of study area was calculated by using equation (2). To process the image, calibration constant $\left(K_{\mathrm{dB}}\right)$, and incidence angle for the pixel position $\left(i_{p}\right)$ were taken from the metadata file (table 1). FRS-1 data was processed to generate $\sigma^{\circ}$ images for $\mathrm{RH}$ and RV. Derived $\sigma^{\mathrm{O}}$ image for $\mathrm{RH}$ is shown in figure 2. $\sigma_{\mathrm{RH}}^{\mathrm{O}}$ ranged from -5.58 to $0.91 \mathrm{~dB}$ with a mean value of $-2.14 \mathrm{~dB}$ and standard deviation of 1.82 (table 4 ).

\subsubsection{Volumetric moisture content $\left(m_{v}\right)$}

The $m_{v}$ for each of the 22 field samples was calculated using TDR calibration curve. Out of these 22 samples, 14 were used for model generation and 8 were used for model validation. Mean $m_{v}$ for each of the 14 sites was 0.28 with standard deviation of 
Table 4. Descriptive statistics of observed variables.

\begin{tabular}{lcrrrr}
\hline & $m_{v}$ & \multicolumn{1}{c}{$\sigma_{\mathrm{RV}}^{\mathrm{o}}$} & \multicolumn{1}{c}{$\sigma_{\mathrm{RH}}^{\mathrm{o}}$} & $\sigma_{\mathrm{RV}}^{\mathrm{o}}-\sigma_{\mathrm{RH}}^{\mathrm{o}}$ & $\mathrm{RMS}_{\text {Height }}$ \\
\hline Mean & 0.28 & -3.79 & -2.14 & -2.17 & 1.65 \\
Standard error & 0.03 & 0.49 & 0.41 & 0.26 & 0.14 \\
Median & 0.29 & -3.47 & -1.81 & -2.24 & 1.70 \\
Standard deviation & 0.12 & 1.82 & 1.55 & 0.96 & 0.52 \\
Sample variance & 0.01 & 3.30 & 2.39 & 0.92 & 0.27 \\
Skewness & 1.13 & -1.24 & -0.43 & -1.04 & 0.37 \\
Range & 0.45 & 7.71 & 6.49 & 3.33 & 2.34 \\
Minimum & 0.14 & -8.52 & -5.58 & -4.35 & 0.60 \\
Maximum & 0.59 & -0.81 & 0.91 & -1.02 & 2.94 \\
Sum & 3.94 & -53.12 & -29.98 & -30.37 & 23.14 \\
\hline
\end{tabular}

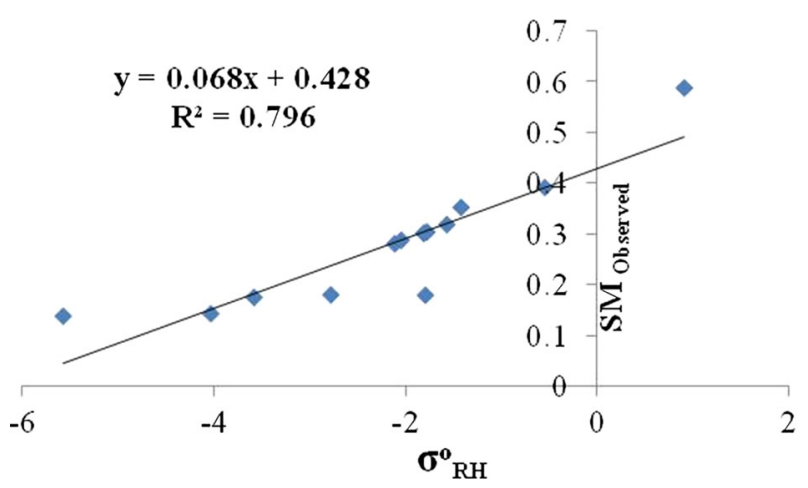

Figure 5. Relationship between backscattering coefficient $\left(\sigma_{\mathrm{RH}}^{0}\right)$ and soil moisture $(\mathrm{SM})$.

$0.16 \mathrm{~m}^{3} / \mathrm{m}^{3}$ and ranged from 0.59 to $0.14 \mathrm{~m}^{3} / \mathrm{m}^{3}$ as given in table 4 .

\subsubsection{Dielectric constant $\left(\varepsilon_{r}\right)$}

The $\varepsilon_{r}$ for each of the samples was calculated by using equation (3) and using frequency-dependent coefficients given in table 2. The $\varepsilon_{r}$ was used for estimating SM using Topp model for comparison of SM estimated with developed model.

\subsubsection{Surface roughness}

The surface roughness $\left(\mathrm{RMS}_{\text {Height }}\right)$ of soil in the area varied from 0.60 to $2.94 \mathrm{~cm}$ with an average value of $1.65( \pm 0.14) \mathrm{cm}$ (table 4$)$.

\subsection{Analysis}

\subsubsection{Relationship between $\sigma_{R H}^{o}$ and $S M$}

Relationship between $\sigma_{\mathrm{RH}}^{\mathrm{o}}$ and SM was developed for $\mathrm{RH}$ polarization and shown in the graph (figure 5). The graph shows that $\sigma_{\mathrm{RH}}^{\mathrm{o}}$ to some extent depends on the SM, having a positive relation. Results showed that $\sigma_{\mathrm{RH}}^{\mathrm{o}}$ increases with increasing SM, with SM explaining about $70 \%$ variations in $\sigma_{\mathrm{RH}}^{\mathrm{o}}$ with a standard error of 0.030 . Thus $\sigma_{\mathrm{RH}}^{\mathrm{o}}$ is directly related to moisture content of the target under consideration. The large datasets of SM measurements have made it possible to establish valid linear relationships between the $\sigma_{\mathrm{RH}}^{\mathrm{o}}$ and SM at each sampling sites.

\subsection{2 $\sigma_{R V}^{o}-\sigma_{R H}^{o}$ relation to soil surface roughness} (SSR)

SSR was calculated in terms of $\mathrm{RMS}_{\text {Height }}$ at each of the sampling sites. The $\sigma^{\circ}$ is sensitive to the $\mathrm{RMS}_{\text {Height }}$, but in the present study it did not show any significant relationship individually with $\sigma^{\circ}$ of $\mathrm{RH}$ and RV polarizations of FRS-1. It may be due to the reason that the area is not having high RMS values $(0.60-2.94 \mathrm{~cm}$, table 4$)$ and the incidence angle of image was high $\left(52.443^{\circ}\right)$ making $\sigma^{\circ}$ independent of $\mathrm{RMS}_{\text {Height }}$ (Aubert et al. 2011; Hosseini et al. 2015). But the difference in backscatter of $\mathrm{RV}$ and $\mathrm{RH}$ polarization $\left(\sigma_{\mathrm{RV}}^{\mathrm{o}}-\sigma_{\mathrm{RH}}^{\mathrm{o}}\right)$ showed significant positive relation with RMS having $R^{2}=0.65$ (figure 4) with standard error of 0.26 (table 4 ).

Table 5. Model summary of generated semi-empirical model (SEM).

\begin{tabular}{lccccc}
\hline Model & Multiple $R$ & $R^{2}$ & Adjusted $R^{2}$ & $\begin{array}{c}\text { Standard error } \\
\text { in estimate }\end{array}$ & Observations \\
\hline SEM & 0.94 & 0.87 & 0.85 & 0.05 & 14 \\
\hline
\end{tabular}




\subsection{Semi-empirical model (SEM) generation}

Correlation and multiple regression analyses were performed to examine the relationship between $\mathrm{SM}_{\text {Observed }}$ and various factors (as mentioned in the above section) for predicting SM using FRS1 dataset of RISAT-1. Table 5 shows the model

Table 6. ANOVA table for dependent factors/ variable in generated semi-empirical model.

\begin{tabular}{lccccc}
\hline & df & SS & MS & F & Sig. F \\
\hline Regression & 3 & 0.16 & 0.05 & 25.26 & 0.00 \\
Residual & 10 & 0.02 & 0.00 & $\mathrm{x}$ & $\mathrm{x}$ \\
Total & 13 & 0.18 & $\mathrm{x}$ & $\mathrm{x}$ & $\mathrm{x}$ \\
\hline
\end{tabular}

Note. df: degree of freedom, SS: sum of square, MS: mean square, F: overall F-test for regression, Sig. F: significance F. summary statistics of new generated SEM. The multiple regression model with all three factors $\left(\sigma_{\mathrm{RH}}^{\mathrm{o}}, \sigma_{\mathrm{RV}}^{\mathrm{o}}-\sigma_{\mathrm{RH}}^{\mathrm{o}}\right.$ and $\left.\mathrm{RMS}_{\text {Height }}\right)$ produced $R^{2}=$ 0.87 , multiple $R=0.94$, adjusted $R^{2}=0.85$, $\mathrm{F}(3$ (regression), 10 (residual) $)=25.26$, Sig. $\mathrm{F}<0.001$ with very low standard error $(=0.05$, table 5$)$.

Analysis of variance (ANOVA) is a variability test. It is the uncertainty that would be present if any one factor is used to predict SM without accounting for change in other factors' role (information). The best one could do is to predict each observation to be equal to the sample mean. The amount of uncertainty/variability can be measured by the total sum of squares (SS, numerator of the sample variance). The ANOVA analysis partitions this variability into two parts as one portion is fitted by the model. It is the reduction in uncertainty that occurs when the regression model is

Table 7. Statistical comparison of generated SM with Topp model based SM.

\begin{tabular}{|c|c|c|c|c|c|c|c|}
\hline Sl. no. & $\mathrm{SM}_{\text {Observed }}$ & $\mathrm{SM}_{\mathrm{Topp}}$ & $\mathrm{SM}_{\mathrm{RISAT}-1}$ & $\sigma_{\mathrm{RH}}^{\mathrm{o}}$ & $\varepsilon_{r}$ & $\boldsymbol{\sigma}_{\mathrm{RV}}^{\mathrm{o}}-\boldsymbol{\sigma}_{\mathrm{RH}}^{\mathrm{o}}$ & $\mathrm{RMS}_{\text {Height }}$ \\
\hline 1 & 0.14 & 0.138 & 0.159 & -3.65 & 10.85 & -1.78 & 1.99 \\
\hline 2 & 0.46 & 0.459 & 0.402 & -0.83 & 33.48 & -1.78 & 1.91 \\
\hline 3 & 0.39 & 0.386 & 0.308 & -0.62 & 27.93 & -2.35 & 0.90 \\
\hline 4 & 0.30 & 0.305 & 0.212 & -1.76 & 22.02 & -2.33 & 0.96 \\
\hline 5 & 0.35 & 0.355 & 0.296 & -1.40 & 25.64 & -4.33 & 0.61 \\
\hline 6 & 0.35 & 0.351 & 0.332 & -1.11 & 25.38 & -3.96 & 0.81 \\
\hline 7 & 0.20 & 0.199 & 0.152 & -3.26 & 14.78 & -3.41 & 1.11 \\
\hline 8 & 0.49 & 0.490 & 0.522 & 0.84 & 35.95 & -3.78 & 0.98 \\
\hline \multirow[b]{2}{*}{ Sl. no. } & \multirow{2}{*}{$\begin{array}{c}\text { Statistical tests } \\
\text { name }\end{array}$} & \multicolumn{6}{|c|}{ Performances of $\mathrm{SM}_{\mathrm{RISAT}-1}$ with respect $\mathrm{SM}_{\text {Observed }}$ and $\mathrm{SM}_{\mathrm{Topp}}$} \\
\hline & & \multicolumn{2}{|c|}{$\mathrm{SM}_{\mathrm{RISAT-1}}$ with $\mathrm{SM}_{\text {Observed }}$} & \multicolumn{4}{|c|}{$\mathrm{SM}_{\mathrm{RISAT}-1}$ with $\mathrm{SM}_{\text {Topp }}$} \\
\hline 1 & RMSE & \multicolumn{2}{|r|}{0.06} & \multicolumn{4}{|c|}{0.10} \\
\hline 2 & R-RMSE & \multicolumn{2}{|r|}{0.18} & \multicolumn{4}{|c|}{0.28} \\
\hline 3 & MAE & \multicolumn{2}{|r|}{0.04} & \multicolumn{4}{|c|}{0.08} \\
\hline 4 & NRMSE & \multicolumn{2}{|r|}{0.17} & \multicolumn{4}{|c|}{0.26} \\
\hline 5 & $\mathrm{MBE}$ & \multicolumn{2}{|r|}{0.04} & \multicolumn{4}{|c|}{0.08} \\
\hline 6 & MAPE & \multicolumn{2}{|r|}{1.39} & \multicolumn{4}{|c|}{2.70} \\
\hline 7 & $\mathrm{~d}$ & \multicolumn{2}{|r|}{1.00} & \multicolumn{4}{|c|}{1.00} \\
\hline 8 & RMSE\% & \multicolumn{2}{|r|}{2.10} & \multicolumn{4}{|c|}{3.26} \\
\hline 9 & NSE & \multicolumn{2}{|r|}{0.91} & \multicolumn{4}{|c|}{0.57} \\
\hline 10 & IR & \multicolumn{2}{|r|}{0.89} & \multicolumn{4}{|c|}{0.78} \\
\hline 11 & $\mathrm{PE}$ & \multicolumn{2}{|r|}{5.61} & \multicolumn{4}{|c|}{5.49} \\
\hline 12 & SEE & \multicolumn{2}{|r|}{0.10} & \multicolumn{4}{|c|}{0.16} \\
\hline 13 & $\mathrm{VE}$ & & 0.15 & \multicolumn{4}{|c|}{0.31} \\
\hline 14 & $\mathrm{~S}_{\mathrm{d}}^{2}$ & & 0.00 & & & 0.06 & \\
\hline 15 & $\mathrm{R}^{2}$ & & 0.87 & & & 0.79 & \\
\hline 16 & $\mathrm{p}($ at $95 \%)$ & & 0.00 & & & 0.01 & \\
\hline 17 & Multi $R$ & & 0.93 & & & 0.89 & \\
\hline 18 & Adj. $R^{2}$ & & 0.85 & & & 0.75 & \\
\hline 19 & Standard error & & 0.05 & & & 0.05 & \\
\hline 20 & t-test & & 3.27 & & & 3.89 & \\
\hline
\end{tabular}




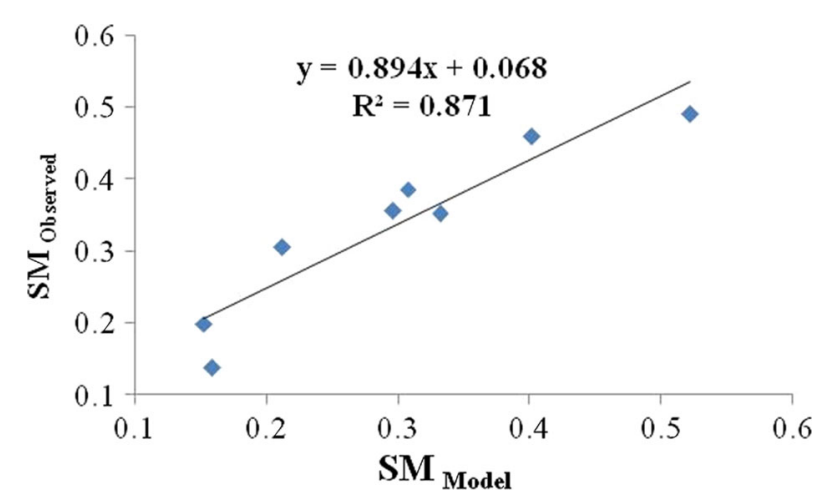

Figure 6. Relationship between $\mathrm{SM}_{\text {Observed }}$ and $\mathrm{SM}_{\text {RISAT-1/Model }}$.

used to predict SM and the remaining portion is the uncertainty that remains even after the model is used. The generated model will be considered statistically significant, if it can show large amount of variability in the SM prediction. Model summary (table 5) and ANOVA test (table 6) reveal that on the basis of $\sigma_{\mathrm{RH}}^{\mathrm{o}}, \sigma_{\mathrm{RV}}^{\mathrm{o}}-\sigma_{\mathrm{RH}}^{\mathrm{o}}$ and $\mathrm{RMS} \mathrm{S}_{\text {Height }}$ factors, an SEM can be generated and is given as:

$$
\begin{aligned}
\mathrm{SM}_{\mathrm{RISAT}-1}= & 0.09 \times\left(\sigma_{\mathrm{RH}}^{\mathrm{o}}\right)-0.05 \times\left(\sigma_{\mathrm{RV}}^{\mathrm{o}}-\sigma_{\mathrm{RH}}^{\mathrm{o}}\right) \\
& +0.14 \times\left(\mathrm{RMS}_{\text {Height }}\right)+0.12
\end{aligned}
$$

where $\mathrm{SM}_{\text {RISAT-1 }}$ is the retrieved soil moisture using FRS-1 dataset of RISAT-1.

\subsection{Statistical validation of developed semi-empirical model (SEM)}

Table 7 shows comparison of observed SM for eight validation points with retrieved $\mathrm{SM}_{\mathrm{RISAT}-1}$ and $\mathrm{SM}_{\text {Topp }}$ along with the results of statistical tests. The statistical analysis showed level of accuracy of developed SEM's SM with respect to $\mathrm{SM}_{\text {Observed }}$ (figure 6) and $\mathrm{SM}_{\text {Topp }}$ (figure 7). The relation in both the cases was significant and positive with SM $_{\text {RISAT-1 }}$ explaining higher variability in observed SM than Topp model. Based on statistical parameters of RMSE, R-RMSE (Rawat et al. 2013; Bala et al. 2015), MAE and MBE statistics test, $\mathrm{SM}_{\text {RISAT-1 }}$ is more closer to the $\mathrm{SM}_{\text {Observed }}$ than $\mathrm{SM}_{\text {Topp }}$ model as indicated by low value of error indices (RMSE $=0.06, \mathrm{R}-\mathrm{RMSE}=0.18$, $\mathrm{MAE}=0.04, \mathrm{MBE}=0.04$ and $\mathrm{SEE}=0.10)$. Higher values of $R^{2}$, Adj $R^{2}$, and Multi $R$ revealed much closer $\mathrm{SM}_{\text {Model }}$ values to $\mathrm{SM}_{\text {Observed }}$ and $\mathrm{SM}_{\text {Topp }}$. Over all, on the basis of statistical tests (table 7), developed model (equation 7) on the

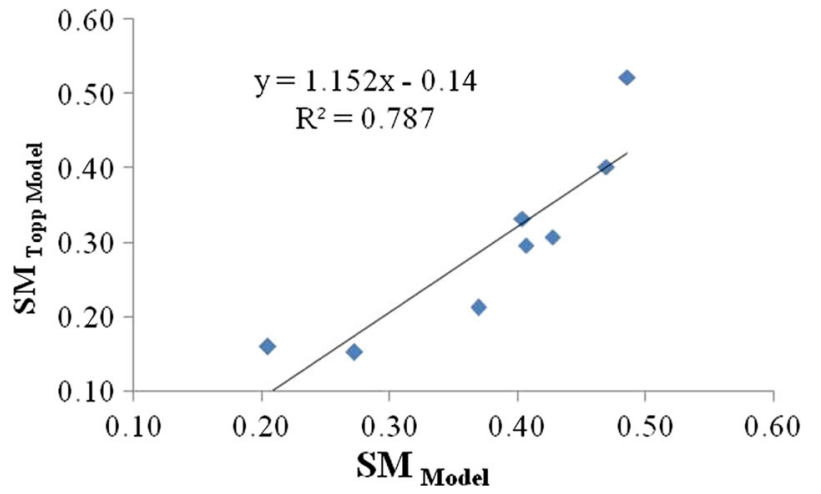

Figure 7. Relationship between $\mathrm{SM}_{\mathrm{RISAT}-1 / \text { Model }}$ and $\mathrm{SM}_{\text {Topp }}$.

basis of $\sigma_{\mathrm{RH}}^{\mathrm{o}}, \sigma_{\mathrm{RV}}^{\mathrm{o}}-\sigma_{\mathrm{RH}}^{\mathrm{o}}$, and $\mathrm{RMS}_{\text {Height }}$ parameters for the study area worked well. By using this SEM, SM value can be predicted with better accuracy. Based on above statistical results (table 7), it can be inferred that the developed SEM model performs better than Topp model for retrieval of $\mathrm{SM}$ at finer resolution.

\section{Conclusion}

Regardless of ground level work, a number of inversion semi-empirical models have been developed to retrieve SM using either passive or active microwave remote sensing. SAR has shown its potential for retrieving SM at regional scales. However, since $\sigma^{\circ}$ is determined by nature of surface, the retrieval of SM is an ill-posed problem when using single factor. The developed method here is more simple and realistic for the estimation of SM. To develop this SEM, major factors considered are $\sigma_{\mathrm{RH}}^{\mathrm{o}}, \sigma_{\mathrm{RV}}^{\mathrm{o}}-\sigma_{\mathrm{RH}}^{\mathrm{o}}$, and $\mathrm{RMS}_{\text {Height }}$.

The main advantage of this inversion scheme is that it requires single field parameters $\left(\mathrm{RMS}_{\text {Height }}\right)$ and it can be easily estimated in comparison with other retrieval approaches. The availability of input parameters is of great importance and also affects the operational results. The SEM parameters need further improvement and they can be improved by using empirical data measured under these conditions. However, any improvement in the algorithm will rely on a better assessment of vegetation influences on the $\mathrm{C}$-band backscattering mechanisms; this needs to take into account the dynamic vegetation effects. The surface variability of $\mathrm{SM}$ was investigated at $3 \mathrm{~m}$ resolution (or 25 $\mathrm{km}$ swath/spot) using in situ measurements and RISAT-1 (FRS-1) derived SM. Despite so many 
sources of errors and several issues, the results obtained by developed semi-empirical model for RISAT-1 FRS-1 data are encouraging.

\section{Acknowledgements}

FRS-1 data procured under RISAT-1 Utilization Programme of ISRO is gratefully acknowledged. The authors would like to express their gratitude to SAC, ISRO (India) for supplying the RISAT1 (SAR) data for this project and also for the financial support. The authors would like to thank Mr. Manish Kumar, project staff and the farm field staff of Division of Agricultural Physics, IARI during field campaigns.

\section{References}

Aubert M, Baghdadi N, Zribi M, Douaoui A, Loumagne C, Baup F, Hajj M El and Garrigues S 2011 Analysis of TerraSAR-X data sensitivity to bare soil moisture, roughness, composition and soil crust; Remote Sens. Environ. 115 1801-1810.

Baghdadi N, Aubert M and Zribi M 2012 Use of TerraSAR$\mathrm{X}$ data to retrieve soil moisture over bare soil agricultural fields; IEEE Geosci. Remote Sens. Lett. 9(3) 512-516.

Bala A, Rawat K S, Mishra A K and Srivastava A 2015 Assessment and validation of evapotranspiration using SEBAL algorithm and Lysimeter data of IARI Agricultural Farm, India; Geocarto Int. 31 1-29, https://doi.org/ 10.1080/10106049.2015.1076062.

Barrett B W, Dwyer E and Whelan P 2009 Soil moisture retrieval from active space borne microwave observations: An evaluation of current techniques; Remote Sens. 1(3) $210-242$.

Blumberg D G, Freilikher V, Lyalko I V, Vulfson L D, Kotlyar A L, Shevchenko V N, and Ryabokonenko A D 2000 Soil moisture (water-content) assessment by an airborne scatterometer: The Chernobyl disaster area and the Negev desert; Remote Sens. Environ. 71 309-319.

Chen Q, Liu J, Tang Z, Zeng J and Li Y 2014 Study on the relationship between soil moisture and its dielectric constant obtained by space-borne microwave radiometers and scatterometers; 35th Int. Symp. Remote Sensing of Environment (ISRSE35), pp. 12-14.

DDMP (District Disaster Management Plan) Rewari 2013 Government of Haryana Department of revenue and Disaster Management, Haryana Institute of Public Administration, Plot 76, HIPA Complex, Sector 18, Gurgaon.

Dente L 2016 Microwave Remote Sensing for moisture mointoring synergy of active and passive observation and validation of retrieved products; Ph.D. thesis, Faculty of Geo-Information Science and Earth Observation, University of Twente.

Dobson M C and Ulaby F T 1981 Microwave backscatter dependence on surface roughness, soil moisture, and soil texture. Part III: Soil tension; IEEE Trans. Geosci. Remote Sens. 19 51-61.
Fung A K 1994 Microwave Scattering and Emission Models and their Applications; Artech House, Nordwood, USA.

Hallikainen M T, Ulaby F T, Dobson M C, El-rayes M A and $\mathrm{Wu}$ L K 1985 Microwave dielectric behavior of wet soil. 1: Empirical models and experimental observations; IEEE Trans. Geosci. Remote Sens. 23 25-34.

Hosseini R, Newlands N K, Dean B C and Takemura A 2015 Statistical modeling of soil moisture, integrating satellite remote-sensing (SAR) and ground-based data; Remote Sens. 7 2752-2780.

Kong X and Dorling S R 2008 Near-surface soil moisture retrieval from ASAR wide swath imagery using a principal component analysis; Int. J. Remote Sens. 29 29252942.

Liu C 2016 Analysis of Sentinel-1 SAR data for mapping standing water in the Twente region; $\mathrm{PhD}$ thesis, Faculty of Geo-Information Science and Earth observation, University of Twente.

Mironov V L, Dobson M C, Kaupp V H, Komarov S K and Kleshchenko V N 2004 Generalized refractive mixing dielectric model for moist soils; IEEE Geosci. Remote Sens. 42 773-785.

Neusch T and Sties M 1999 Application of the Duboismodel using experimental synthetic aperture radar data for the determination of soil moisture and surface roughness; ISPRS J. Photogramm. Remote Sens. 54(4) $273-278$.

Nussberger M 2005 Soil moisture determination with TDR: Single-rod probes and profile reconstruction algorithms; $\mathrm{PhD}$ dissertation submitted to the Swiss Federal Institute of Technology ZURICH, Switzerland.

Rawat K S, Mishra A K, Sehgal V K, Ahmed N and Tripathi V K 2013 Comparative evaluation of horizontal accuracy of elevations of selected ground control points from ASTER and SRTM DEM with respect to CARTOSAT-1 DEM: A case study of Shahjahanpur (Uttar Pradesh), India; Geocarto Int. 28 439-452.

Rawat K S, Sehgal V K, Pradhan S and Ray S S 2017a Retrieval and validation of soil moisture from FRS-1 data set of radar imaging satellite (RISAT-1); Arab. J. Geosci. 10 445, https://doi.org/10.1007/s12517-017-3195-6.

Rawat K S, Bala A, Singh S K and Pal R K 2017b Quantification of wheat crop evapotranspiration and mapping: A case study from Bhiwani District of Haryana, India; Agr. Water Manag. 187 200-209.

Saleh A 1993 Soil roughness measurement: Chain method; J. Soil Water Conserv. 48CG 527-529.

Sikdar M and Cumming I 2004 A modified empirical model for soil moisture estimation in vegetated areas using SAR data; In: Geoscience and Remote Sensing Symposium 2004, IGARSS'04 Proceedings 2 803-806.

Singh D and Kathpalia A 2007 An efficient modeling with GA approach to retrieve soil texture, moisture and roughness from Ers-2 SAR data; Prog. Electromagn. Res. 77 121-136.

Srivastava H S, Patel P and Navalgund R R 2006 How far SAR has fulfilled its expectation for soil moisture retrieval? Microwave Remote Sensing of Atmosphere and Environment-II, AE107, Asia Pacific Remote Sensing Symposium, 12p.

Topp G C, Davis J L and Annan A P 1980 Electromagnetic determination of soil water content: Measurements 
in coaxial transmission lines; Water Resour. Res. 16(3) $574-582$.

Ulaby F, Moore R K and Fung A K 1982 Microwave Remote Sensing: Active and Passive. Vol. II, Radar Remote Sensing and Surface Scattering and Emission Theory; Addison-Wesley, Advanced Book Program, Reading, Massachusetts, 609p.

Ulaby F T, Batlivala P P and Dobson M C 1978 Microwave backscatter dependence on surface roughness, soil moisture and soil texture. Part I: Bare soil; IEEE Trans. Geosci. Remote Sens. 16(4) 286-295.

Corresponding editor: Prashant K SRIVAStava
Werrer J and Andreas K 2005 Soil surface roughness measurement-methods, applicability, and surface representation; Catena 64 174-192.

Zhang X, Chen B, Fan H, Huang J and Zhao H 2016 The potential use of multi-band SAR data for soil moisture retrieval over bare agricultural areas: Hebei, China; Remote Sens. 8(1) 1-14.

Zribi M and Dechambre M 2002 A new empirical model to retrieve soil moisture and roughness from C-band radar data; Remote Sens. Environ. 84 $42-52$. 